\title{
El azar y la teoría
}

José M anuel Rodríguez

Universidad de Concepción

\section{Resumen}

El sueño de la historia, novela de Jorge Edwards, narra, por un lado, la relación, de fines de la Colonia, entre Joaquín Toesca, el arquitecto y constructor del palacio de La M oneda y su desacatada esposa M anuela Fernández, y por otro lado, cuenta la vida de "EI $\mathrm{N}$ arrador" a fines de la dictadura que azotó a C hile. El ensayo que sigue está dividido en "tres avenidas de sentido", en las cuales se exploran diferentes posibilidades de operar con el texto de Edwards. D e tales avenidas, sin duda, la más importante es la que se interna en las relaciones intertextuales del texto. Dicha importancia radica en que EI sueño de la historia tiene un origen jamás nombrado por su autor, esto es una oscura novela histórica, La Pequeña Q uintrala deJ oaquín Toesca, escrita por una antigua dama deC oncepción, Ilda Cádiz Avila. El texto de Cádiz así leído no es sólo el origen del de Edwards, sino que éste realiza un verdadero plagio sobre el primero. El estudio explora, además, cuál es el sistema narrativo que opera en el texto matriz de la investigación y cuáles son los sentidos del robo para la teoría contemporánea.

Palabras Claves: N arración, plagio, azar, intertextualidad.

\section{ABst RACt}

El sueño dela historia, a novel by JorgeEdwards, narrates, on the one hand, the relation between Joaquín Toesca, the XVIII century architect of La M oneda palace, and his unruly wife M anuela Fernández, and, on the other hand, the life of "El N arrador" towards the end of the C hilean military dictatorship. The paper is divided into three "avenues of sense", in which different possibilities of experimenting with Edwards' text are explored. From these avenues, the most important one is the one that explores the intertextual relations found in the text. The significance of this lies in the fact that El sueño dela historia has an origin never mentioned by its author: an obscurehistorical novel - La Pequeña Q uintrala de Joaquín Toesca- written by Ilda C adiz Avila, an elderly lady from Concepción. Cadiz' text is not only the point of departure of $E$ dwards' text: the latter simply plagiates the former. The study al so explores the narrative system that operatesin theanalyzed text, and examinesthe meanings of "stealing" in contemporary theory.

KEYWORDS: N arration, plagiarism, chance, intertextuality.

Recibido: 14.01.2003. Aceptado: 24.02.2003. 


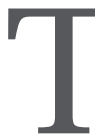

ARD EW SKI sostiene que el azar se parece a "la inesperada asociación de dos hechos aislados, de dos hechos que al unirse producen al go nuevo. En este caso se trataba de dos textos leídos de modo sucesivo y casual"1. Esos dos textos fueron una carta de Kafka y una biografía de H itler. Lo nuevo fue el descubrimiento, producido en la asociación de la lectura, del encuentro entre el escritor y el hijo de la muerte dado hacia 1910. Tal hallazgo permite aTardewski construir una compleja tesis sobrelas relaciones entre literatura, filosofía y nacionalsocialismo (si es que admite nombre esta cosa).

Pensamos que nos sucedió algo parecido, en menor escala. Leímos El sueño de la historia² de Edwards y la novela me impresionó profundamente, adscrita al género histórico, texto maduro, hábilmente desarrollado, pleno de referencias a la historia de este lugar Ilamado $C$ hile. D e hecho, el relato se plantea en dos tiempos distintos de la historia de C hile:

1. La Colonia tardía e inicios de la república.

2. La dictadura tardía y regreso de la democracia.

La fábula se inicia con el retorno a Chile del personaje principal, "El $\mathrm{N}$ arrador", a fines de la dictadura. "El N arrador" es un hombre en la mediana edad, escritor, pertenece a la clase al ta y se encuentra separado de C ristina, su mujer, "militante comunista furiosa". Ellos son los padres de I gnacio, personaje que sufre la cárcel y, luego, parte al autoexilio.

Ya en Santiago, arrienda un viejo departamento frente a la plaza de armas. El inmueble había pertenecido a un historiador fallecido hace poco. Entre los papeles del difunto encuentra una causa de 1780 y tantos donde litigan Joaquín Toesca, el arquitecto de La M oneda, y su mujer M anuela Fernández, acusada de envenenar a su marido con el fin de poder entregarse a sus excesos amatorios.

"El N arrador" sefascina con la historia de M anuela, fémina felina, y se da al trabajo de contarla. Esta narración constituye uno de los macrorrelatos que configura el texto. El otro se construye sobre la vida del "N arrador" en el Chile bajo el poder cívico-militar. Aquí se describen, en detalle, las relaciones familiares de aquél. Relaciones organizadas, básicamente, en torno a su mujer, C ristina; su hijo, I gnacio; su padre, I gnacio; y su hermana, $\mathrm{N}$ ina. EI

${ }^{1}$ Tardewski. "Teoría y periferia”. En Respiración artificial. Piglia, Ricardo. Planeta. Buenos Aires. 1998.

Edwards, Jorge. El sueño de la historia. Tusquets. Barcel ona. 2000. 
relato contemporáneo tiene un carácter englobante y total izador y corresponde al "supranarrador", quien examina, reconstruye e indaga en la vida de sus personajes, estableciendo relaciones entre el mundo colonial y el moderno. Sobre este argumento se expande esta interesante novela.

A partir de este material inicié mis trabajos, luego, gracias al editor 0 scar Lermanda, llegó a nuestras manos La Pequeña Q uintrala de Joaquín Toesca ${ }^{3}$ de C ádiz. Lo raro es que el texto de Edwards se parece demasiado a la novela de Cádiz. Comprendemos entonces que el azar, como le llaman algunos a esa infinita sucesión de juegos con que los dioses se ríen de los hombres, había cambiado, una vez más, una versión sobre la realidad, para el caso, este ensayo, gracias a la lectura de dos textos leídos de modo sucesivo y casual.

Ahora, sabemos quetoda versión sobre la realidad está organizada por un principio teórico (El orden puede invertirse respecto de ciertos fenómenos sociales, es decir, primero surge una tendencia y luego asoman las consignas quelo organizan). La versión que sigue se basa en una teoría emanada de una máquina del género crítico, generadora demúltiples aparatosteóricos, Roland Barthes. Una de las formas de aproximación a la literatura que él propone es el análisis textual, sistema que "no procura describir la estructura de una obra... no intenta averiguar qué es lo que determina al texto sino saber cómo estalla y se dispersa... nosotros tomaremos un texto narrativo procurando distinguir y clasificar sin rigor no todos los sentidos del texto... sino las formas, los códigos, según los cuales los sentidos son posibles. N osotros vamos a distinguir las avenidas del sentido"4. L as disposiciones operatorias del análisistextual así entendido son, fundamentalmente, "desplegar el hojaldramiento del texto y mostrar las partidas de sentido más que sus llegadas" 5 .

Siguiendo la propuesta barthesiana, intentamos a continuación generar un hojaldramiento de un objeto, El sueño de la historia, a fin de mostrar al gunas de las innumerables avenidas de sentido que, al igual que todo tejido de palabras, esta novela inaugura.

El lector, en este punto se puede preguntar: ¿Y qué me importa la teoría? Si lo que interesa es esa relación no confesada y anunciada, ese texto oscuro, ese libro que Edwards mantiene, hasta hoy, en secreto. Contestamos: somos teóricos y nos debemos al oficio.

Por lo demás, lo otro será tratado en extenso, mas traspasado por la teoría.

${ }^{3}$ Cádiz Avila, Ilda. La Pequeña Q uintrala de oaquín Toesca. Editora Aníbal Pinto. C oncepción. 1994.

"Barthes, Roland. "Analysetextuelled' un conted' Edgar Poe". En: Alexandrescu, Barthes, Bremond et alli. Semi otique narrativè et textuelle. Paris. Larousse. 1973, pp. 29.

${ }^{5}$ Barthes, 1973, 36. 


\section{PRIMERA AVENIDA LA MARCA DEL PODER}

I niciamos el hojaldramiento desplegando el sistema narrativo que opera en el texto, el que está organizado según un procedimiento denominado por el propio autor deEI sueño de la historia, la "invención del narrador": "En todo texto narrativo la invención primera, la principal y esencial, la condición previa, sin la cual el texto no podría salir dela nada esla del narrador, si ustedes quieren la voz narrativa... La invención, que algunos Ilaman la elección, pero es la elección de un invento, del punto de vista del narrador, determina el tono de toda la obra" ${ }^{6}$. D iscutir sobre el carácter del narrador nos interesa sobremanera. Si acudimos a la teoría, ella nos enseña que aquél es el "sujeto de esa enunciación que representa un libro"7. Es decir, es el que maneja la enunciación, el que la posee, en suma, el que "elige contarnos tal o cual peripecia, a través del diálogo de dos personajes o bien mediante una des-

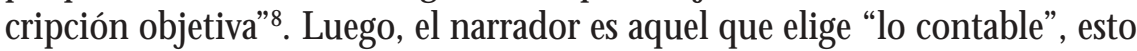
es, será quien funcione como una "marca de poder en el discurso, un foco que alumbra al gunas zonas y oscurece otras de la materia narrativa" ${ }^{\text {. Este }}$ foco funciona plenamente como elemento propio de una práctica novelística, el realismo, y, muy especialmente, de la novela de aprendizaje.

Sin embargo, Edwards no se rinde tan fácil al realismo, pues notamos un afán, en el relato, por mostrar queel "supranarrador" no lo sabetodo. Laforma en que aquél se organiza constituye, en este aspecto, un inteligente ejercicio por acotar la "dimensión" de su omnisciencia en tanto marca de poder. En primer término, el "supranarrador" tiene un carácter extradiegético que oscila entre heterodiegético y homodiegético. Es decir, de narrador en primer grado ausente de la historia deviene narrador en el mismo grado presente en la historia. Esta oscilación se observa en los medios usados en la inclusión de narrador intradiegético: "El, el historiador aficionado, el narrador en proyecto, ya había bebido tres whiskies dobles"10 (extradiegético - heterodiegético). O bviamente, no está "hablando" el "narrador en proyecto", el cual se va

${ }^{6}$ Edwards, Jorge. "La invención del narrador". En Atenea N 483. Primer semestre del 2001. Universidad de Concepción.

${ }^{7} T$ odorov, Tzvetan. En: Barthes, Bremond, Greimasy otros. Análisisestructural. Fondo de Cultura Económica. M éxico. 1970.

${ }^{8}$ Todorov, 1970, 56.

${ }^{9}$ Rodríguez, M ario. C urso: “Borges, Paz, Piglia”. D octorado en Literatura. Inédito. U niversidad de Concepción. 2000.

${ }^{10}$ Edwards, 2000, 29. 
constituyendo de a poco en "N arrador" a secas. M ás adelante leemos: "Tendrá que pagar las consecuencias, se diceel N arrador... "11. O bservamos, nuevamente, quesobre estesujeto opera otro sujeto dela enunciación. Asunto quela novela transparenta en: "Pero el Narrador, aquí, ¿o nosotros en lugar suyo? opta por suspender el juicio... "12 (extradiegético - homodiegético). La anunciada transparencia alcanza la obviedad en: "EI N arrador (y nosotros con él, a pocos centímetros de distancia, mirando por encima de su hombro)..."13. El artificio de instalar este narrador intradiegético permite al texto emprender la deflación del "supranarrador". Proposición que sustentamos en:

1. "El N arrador no sabe, encerrado en su repostero, y nosotrostampoco... "14.

2. "En qué Colonia me habré metido, suponemos que pensaba... "15.

Con la primera cita evidenciamos la relación de subordinación del "N arrador" al "supranarrador". Con la segunda cita mostramos el proceso de deflación, que implicaría la pérdida de la omnisciencia del "supranarrador" y, por tanto, una intención de instalar en el texto la ambigüedad. Esta intención expuesta en la novela se respalda en la idea de narrador que tiene el autor, quien a propósito de M achado deAssis sostiene un ideal: "Inventar un narrador lúcido, libre, dotado de sentido del humor y de ideas personales, no impostadas ni copiadas, que cuenta desde una distancia, que sabe combinar la frialdad con la pasión..."16. Se observa que el autor privilegia un narrador lúdico que maneja la temperatura del relato. Es decir que no se quema con nadie. En este aspecto, El sueño de la historia se parece peligrosamente a dos textos anteriores. Para mostrar tal parecido, usaremos un ensayo de JoséPérez Bowie sobre G oytisolo ${ }^{17}$. En este interesante artículo Pérez muestra una de las técnicas narrativas que animan dos "metaficciones"18 historiográficas: El valle de los caídos ${ }^{19}$ y la Autobiografía del general Franco ${ }^{20}$. D icha técnica consisteen "la diversificación en dos planos narrativos. El del universo represen-

${ }^{11} \mathrm{E}$ dwards, 2000, 40.

${ }^{12} \mathrm{E}$ dwards, 2000, 35.

${ }^{13}$ Edwards, 2000, 303.

${ }^{14} \mathrm{E}$ dwards, 2000, 240.

${ }^{15} \mathrm{E}$ dwards, 2000, 23.

${ }^{16} \mathrm{E}$ dwards, 2001, 12.

${ }^{17}$ Pérez Bowie, José. "¿La inviabilidad de la novela histórica? La saga de los M arx de Juan G oytisolo". En: La novela histórica de finales del siglo XX, pp. 339-349.

${ }^{18}$ U samos el nombre que da H utcheon a la novela histórica.

${ }^{19}$ Rojas, Carlos. El valle de los caídos. D estino. Barcelona. 1978.

${ }^{20}$ V ázquez M ontal bán, M anuel. Autobi ografía del general Franco. Planeta. Barcelona. 1992. 
tado y el del personaje contemporáneo que como narrador lo elabora para nosotros... ". O bservamos la presencia de la misma macroestructura anotada en el resumen del texto matriz de la investigación, es decir, dos narradores, uno que cuenta el pasado y otro el presente. Luego, Pérez Bowie anota queel proceso no está totalmente logrado: "El ensamblaje de ambos núcleos narrativos no se articula en una estructura netamente metaficcional ya que la voz responsable de las páginas históricas es una voz anónima... Esta dimensión metanarrativa la posee, en cambio, plenamente la Autobiografía del general Franco, de M anuel Vázquez M ontalbán"21. En El sueño dela historia la dimensión metanarrativa se logra por la inclusión de una voz que no es anónima, "El Narrador", quien relata, parcialmente ${ }^{22}$, los sucesos del pasado. Ello lo confirmamos cuando, en un momento de la narración sobre la vida deToesca y $M$ anuelita, seinterrumpeel relato y se lee: "EI N arrador, I gnacio Segundo en su breve dinastía o I gnacio el I nútil, lanza su lápiz encima de los papeles, bosteza, se estira... "23. O bservamos claramente que el sujeto de la enunciación de la historia era "El N arrador".

En la Autobiografía del general Franco, de acuerdo a Pérez Bowie, la dimensión metanarrativa se logra por el uso de un recurso similar, es decir, instalar como sujeto de la enunciación histórica a un narrador intradiegético que se ubica en el presente y que se relaciona críticamente con éste. Ahora lo interesante es que esta instalación tiene un objetivo bastante peculiar: "Esta compleja estructura responde a una evidente función perspectivística... el autor ha pretendido 'enfriar' su acercamiento a un personaje y a unos acontecimientos históricos demasiado próximos en el tiempo, y capaces, por ello, de suscitar aún pasiones... "24.

Recordemos, ahora, que usamos el condicional cuando explicamos cuál sería el objetivo de la deflación del "supranarrador". Tal uso se explica, al parecer, en la intención de formalizar un procedimiento que permita al Sue ño de la historia (al "supranarrador" que lo domina) "enfriar" su acercamiento a un personaje, Pinochet ${ }^{25}$, y a unos acontecimientos demasiado recientes, la dictadura y sus efectos. Acontecimientos aún próximos en el tiempo y que, por ello, todavía suscitan pasiones en este lugar de la tierra llamado Chile. Recordemosque el autor de la novela privilegia un narrador que "sabe

${ }^{21}$ Pérez Bowie, p. 338.

${ }^{22}$ D ecimos parcialmente, pues ya vimos que el "supranarrador" es quien mantiene el control del relato.

${ }^{23}$ Edwards, 2000, 179.

24 Pérez Bowie, 2000, 339.

${ }^{25} \mathrm{~N}$ ombre que asumió la tortura, el horror, la ambición y la muerte en Chile. 
combinar la frialdad con la pasión". La pasión se inscribe en El sueño de la historia por medio de una cierta tendencia a "entibiar" el relato, mostrando el horror, pero esta tendencia se disfraza, se oculta dentro de una reflexión, también opaca, sobre el lado salvaje de la sociedad, del país y de la historia ${ }^{26}$. La frialdad se anota en la forma en que trata el tiempo del horror. Ello lo justificamos en:

a) La mayoría de los sintagmas en que se alude en forma directa a la tiranía están entregados a la mujer del "N arrador", la cual es definida como "militante comunista furiosa; "dinamitera", etc.

b) El único sintagma en que se marca una acusación directa al ladrón del sillón de Salvador Allende, Pinochet, está entregado a un personaje "pintoresco".

c) El texto para referirse "al asesino" Pinochet usa, varias veces, el absurdo mote con el que, aún, Io llama la prensa afín: "El Caballero".

d) Por último, existe un reconocimiento, por parte del "supranarrador", a la actitud del tirano cuando sometió a plebiscito la posibilidad de eternizar su régimen: "El plebiscito, que decidirási el dictador sequeda en su asiento de La M oneda o se va con toda clase de resguardos, con sus espaldas bien protegidas, pero dejando paso a un Presidente elegido... "27. N otamos, a partir de las citas anteriores, que la novela "enfría" en su relación con la dictadura. Incluso se plantea un cierto reconocimiento a la "transición" ofrecida por el tirano.

Consideremos, entonces, queel complejo sistema narrativo responde más a una intención "política" que a un afán de fragmentar los sentidos posibles del texto. Práctica propia de la novela realista.

Al respecto, Susan Suleiman, en La structure d' apprentissage ${ }^{28}$, sostiene, a partir de su análisis de L' étape ${ }^{29}$, que "les systhèmes semiologiques représentés àl' intérieur dela diégèse soient eux mêmesintégrés dansun 'super-systhème' de l'oeuvre...". Luego, este supersistema será asumido por un "narrateur omniscient". Esta conformación se llamará "super-systhème du narrateur". A este supersistema es el que se adscribeel "supranarrador". A hora, el porqué

${ }^{26}$ Este punto sería lato de desarrollar aquí, dejamos como referencia nuestra tesis de grado, sobre este mismo tema, titulada "L os de arriba suben. Los de abajo, bajan". U niversidad de Concepción. 2002. Inédita.

${ }^{27} \mathrm{E}$ dwards, 2000, 303.

${ }^{28}$ Poétique N 0 37. Febrero de 1979, pp. 24-42.

${ }^{29}$ Bourget, Paul. L' étape. París. 1902. 
dela función plena de este tipo de narrador es atribuido a la novela de aprendizaje y está dado en razón de que esta praxis escritural es propia de una sociedad disciplinaria ${ }^{30}$, la cual tiene por obsesión la formación de un sujeto dócil que se inserte en el orden dominante. Suleiman sostiene que el aprendizaje es positivo cuando el sujeto ingresa al orden y negativo cuando no lo logra.

El análisis de la función del "supranarrador" que opera en el texto es, entonces, la primera lexia, que hace posible un sentido, una lectura de El sueño de la historia. Comprendiendo lexia como: "un producto arbitrario, un segmento en el interior del cual se observa la repartición de los sentidos; es lo que los cirujanos Ilamarían un campo operatorio: Ia lexia útil es aquella donde no encontramos más que uno, dos o tres sentidos... la lexia no abarcará más que unas pocas palabras o unas cuantas frases: bastará que constituya el mejor espacio posible donde se puedan observar los sentidos"31. Esas "cuantas frases" están en: "El N arrador, si todavía estuviese entre nosotros, si no hubiera resuelto, en una de las páginas finales, ingresar al orden... "32. A prendizaje positivo, un personaje que, como veremos más adelante, se instala en la resistencia, termina por adscribirse al sistema dominante. O bservamos que la novela mostraría que no es capaz de superar el realismo y el orden discursivo que la contamina. No se convierte en un espacio de resistencia y termina por plegarse al poder.

En este punto volvemos a Foucault. Este particular cirujano invita al teórico de la literatura a "estudiar en sí mismas, en su juego y en sus luchas, estas voces de la transfábula, cuyo intercambio dibuja la trama de la ficción" ${ }^{33}$. Es

${ }^{30}$ Foucault, M ichel. Vigilar y castigar. Siglo XXI. M éxico.1992. A este respecto, en general, Foucault expone que han existido, en Europa, últimamente, a lo menos tres tipos de sociedades:

1. Las de soberanía: sometidas al poder de un soberano cuyas labores de vigilancia eran similares a las de un pastor que cuidaba al pueblo (sus ovejas).

2. Las disciplinarias: Fundadoras del principio "vigilar y castigar". A poyadas en tecnologías como el panóptico basado en la idea mirar sin ser mirado, que un solo hombre pueda vigilar a muchos. La sociedad disciplinaria se inscribe sobre los cuerpos, estableciendo penas, condenas a los transgresores de toda norma. Fruto de las sociedades de este tipo son la escuela, el hospital y la prisión. M ario Rodríguez agrega: la novela de aprendizaje.

3. Las de control: En la sociedad moderna, la tecnología del control va a ser algo así como el "Big Brother". Las complejidades del concepto se encuentran en un problema de "vel ocidad". Ya no estamos en la era del hombre del carbono, ahora es la era del hombre del silicio, es decir, de aquél cuya vida está asociada a velocidades informáticas.

${ }^{31}$ Barthes, 1973, 31.

${ }^{32} \mathrm{Edwards}, 2000,412$.

${ }^{33}$ Foucault, M ichel. "La transfábula". En: D e lenguaje y literatura. Paidós. Barcelona. 1992, p. 217. 
decir, nos induce a observar cómo se relacionan los diversos narradores que articulan un sistema narrativo cualquiera. A hora, el sistema narrativo que se articula en El sueño de la historia provoca que esta novela se inscriba, a pesar de todos los juegos de superficie, en el más puro de los realismos que anunciábamos al principio del análisis. Será, entonces, el "supranarrador" una marca de poder, una instalación panóptica que todo lo vigila y observa. Una instancia disciplinaria que genera "un efecto de deslizamiento que hace que aceptemos como verdad no sólo lo que el narrador nos dice de la acciones y delascircunstancias del universo diegético, sino también todo lo queél enuncia como juicio o como interpretación. El narrador llega a ser de esta manera no sólo recurso de la historia sino también intérprete último del sentido de esta" ${ }^{34}$. Edwards termina por traicionar una máxima: "escribir es resistir", pues el discurso no debería intentar legitimarse en términos de verdad sino en términos de consistencia interna, porque cuando busca la verdad produce efectos de poder y el efecto de poder que produce El sueño de la historia es la legitimación última del orden burgués: el narrador ingresa al orden. En cambio, la novela transgresiva invierte la sentencia del aprendizaje: éste es negativo cuando el personaje se adscribe al orden y positivo cuando intenta la fuga hacia las zonas oscuras, es decir, aquéllas donde no lo alcanza el faro del poder.

Se ha producido un quiebre entre el autor y nosotros, pues el acto de no aceptar la inducción a una verdad que emana del texto "equivale a una ruptura de contrato por parte del lector. Esta especie de ruptura siempre es posible, y llega a ser incluso inevitable si el sistema de los valores del lector está en una relación conflictiva con la del narrador. En este momento, la lectura novelesca se transforma en otra cosa, porque el lector percibe la obra como una tentativa demasiado evidente de manipulación. El contrato de la novela realista exige que el lector se ciegue voluntariamente con respecto a los procedimientos del novelista; afirmando repentinamente sus propios val ores frente a los valores preconizados por la obra, el lector rompe el contrato y rechazando su ceguera voluntaria acusa al novelista de haber trucado su juego. Paradojalmente, es en este preciso momento, cuando sus convicciones reales irrumpen en su lectura, que el lector de novelas toma plena conciencia de los artificios de la ficción" 35 .

H emos tomado conciencia de los artificios de la ficción, los que pretenden encubrir, "suavizar", como dijimos, los horrores de la tiranía. Se empieza a romper el contrato entre este ensayo y El sueño de la historia.

${ }^{34}$ Suleiman, 1979, 28.

${ }^{35}$ Suleiman, 1979, 29-30. 


\section{SEG UN D A AVEN ID A LA INTERT EXT UALID AD}

Julia K risteva sostiene que "tout texte se construit comme mosaïque de citations, tout texte est absorption et transformation d' un autre texte. A la place de la notion d' intersubjectivité s' installe celle d' intertextualité, et le langage poétique se lit, au moins, comme double" ${ }^{\prime \prime 3}$. En esta intertextual idad el lenguaje poético aparece como "un dialogue de deux discours. Un texte étranger entre dans le reseau de l' escriture..." "37. El diálogo textual genera, entonces, que en cada texto en específico, en su paragrama, estén "tous les textes de l' espace lu par l' ecrivain... "38. A hora, la forma en que un texto lee a los anteriores origina distintos tipos de intertextualidad. Pero aclaramos que nos interesa destacar, más que nada, sólo un texto "le par l'ecrivain", y, por supuesto, indagaremos en la intertextualidad que genera.

a) Interesante es la relación intertextual que encontramos en el epígrafe del texto anota: “ ¡O h, qué tiempos serán aquéllos! ¡Q ué obscuridad! ¡Q ué temor! ¡Q uétentación! ¡Q ué peligro!... M anuel de L acunza, La Venida del M eśas en Gloria y M ajestad" ${ }^{39}$. Extraña referencia la de EI sueño de la historia. Este curioso texto de Lacunza tiene un afán escatológico, disciplina teórica que se puede entender como "parte de la teología que estudia las últimas cosas, es decir, el destino final del hombre y del universo" ${ }^{40}$. Luego, ¿se habrá equivocado Lacunza en su profecía y en vez de un M esías llegó un D ictador? ¿Estará Edwards insinuando, oscuramente, el destino final de Chile: sucumbir a un "Viejo de M ierda", monstruo incubado en "la mugre de siglos"? ?". Porque claramente no es casual que ese soldado, es decir, un representante mayor de la disciplina, gobernase el país por tanto tiempo y con tanto apoyo. Fascinante avenida de sentido la hojaldrada en el texto, sin embargo, al igual que en el acápite anterior, sólo la dejamos insinuada, pues vamos a otra zona de la novela.

${ }^{36}$ K risteva, Julia. Recherches pour une Sëmanalyse. Editions du Seuil. París. 1969, pp. 145-183.

${ }^{37}$ K risteva, 1969, 181.

${ }^{38}$ K risteva, 1969, 183.

${ }^{39} \mathrm{Edwards}, 2000$, 8.

${ }^{40} \mathrm{D}$ iccionario Encarta. M icrosoft. 2002.

${ }^{41} \mathrm{H}$ emos estudiado las relaciones escatológicas que El sueño de la historia desarrolla. C omo referencia remitimos a nuestra tesis ya mencionada. Interesa señalar que la segunda entrada del $D$ iccionario Encarta señala que escatología se puede entender como "estudio de los excrementos". 
b) Ahora aten deremos a la intertextual idad más polémica que hemos encontrado en El sueño dela historia. Recordemos queK risteva, la notable, sostiene que la lectura de otros textos en un texto determinado es la materia de la intertextualidad. Esta lectura es necesaria enten derla en el sentido etimológico del término: "Le verbe 'lire' avait, pour les Anciens, une signification que mérite d'éter rappelé et mise en valeur... 'Lire' étit aussi 'ramasser', 'cueillir', 'epier', 'voler'... Lire dénote, donc, une participation agressive, une active appropriation de l'autre... "42. Luego, la escritura intertextual puede operar como: "citation (avec guillements, avecou sans réfèrence précise; sous une forme moins explicite et moins canonique, celle du plagiat)"43. Este sería "le voler", "une active appropriation de l'autre", de que nos hablaba K risteva. Apropiación que se marca en El sueño de la historia por la forma en que "lee a la historia y se inserta en ella"44. Pues ya sabemos que la historia de Toesca y la $M$ anuelita no fue encontrada en viejos papeles del pasado como anuncian las investigaciones del "N arrador-hard boiled", alter ego del autor ${ }^{45}$, sino en una oscura "metaficción historiográfica", ya nombrada en la introducción, La Pequeña Q uintrala de J oaquín Toesca. Sabemos, incluso, que Jorge Edwards vino a Concepción en 1994 y se llevó consigo el manuscrito de Cádiz. El editor O scar Lermanda era muy amigo de la escritora. El fuequien editó la primera y única edición del texto de Cádiz, de la cual queda un par de ejemplares, uno de ellos en nuestro poder. Cuenta, incluso, que la escritora, después de entregar sus manuscritos a Edwards, le comentó que el escritor seguramente iba a escribir una novela con el material.

Intentaremos reconstituir el hallazgo del texto de Cádiz por Edwards. En la entrevista, ya citada, al diario El M undo, leemos: "Edwards se asombró cuando conoció la historia de Toesca y $\mathrm{M}$ anuelita en $\mathrm{H}$ istoria del arte en $\mathrm{e}$ Reino de Chile, texto que le mencionó un amigo de la Academia de H istoria... para el novelista descubrir esta historia fue apasionante: 'H e estudiado arquitectura, he viajado a París para llenarme del estilo neoclásico... Ilevo años trabajando en esto. Soy muy lento para escribir'..." "46. C reemos que hasta la mención al académico que le habló de la historia de M anuelita Edwards se mantiene en el plano de la anécdota. D e ahí en adelante se inicia

${ }^{42} \mathrm{~K}$ risteva, 1969, 181.

${ }^{43} \mathrm{G}$ enette, G érard. La Litterature au Second D egré. Editions du Seuil. París 1982, p. 8.

${ }^{44} \mathrm{~K}$ risteva, Julia. "N arración y transformación”. En Semiótica N ํ 4, pp. 422-448. París. 1969.

${ }^{45}$ Jorge Edwards, al respecto, señala: "M uchas cosas que le pasan al narrador las ha vivido a mi regreso". En: "La Cultura". El M undo. M adrid. 4 de abril del 2001.

${ }^{46 " L a}$ Cultura", 4 de abril del 2001, pp. 12. 
la simulación. O bservemos ahora cómo El sueño de la historia transforma, oculta, el encuentro efectivo del autor con los afanes deToesca y $M$ anuelita. Ya dijimos, en el argumento, que "el N arrador se fascinó" con dichos afanes, cuyo relato fue encontrado en los papeles que tenía el viejo historiador. El problema es que "los papeles del historiador decían bastante, pero no lo suficiente... Partió, pues, el lunes siguienteal Edificio del Archivo $\mathrm{N}$ acional, donde le recomendaron que hablara con una señora de mediana edad, de anteojos gruesos, de uñas barnizadas, que entendía de esos asuntos..." ${ }^{47}$. Asistimos a la transformación de la historia, pues la ayuda proporcionada por la señora de anteojos gruesos al "N arrador alter-ego", es decir, a Edwards, fue la siguiente:

- Concepción me vive importunando con este cuento de la M anuelita, ella está escribiendo una novela sobre el asunto.

-Edwards: Ah (con indiferencia)... ¿ ¿y cómo se llama la señora?

- Señora de uñas barnizadas: Ilda C ádiz. Ella es de Concepción... , etc.

Q uizás fue así como el autor deEI sueño dela historia supo de los estudios de Ilda y, por ende, decidió visitarla. D e vuelta a la capital Ilevaba la materia sobre la cual organizaría su novela.

Es decir que la pretendida investigación, anunciada en el texto y en los diarios, no existe. Sólo asistimos a una forma agresiva de intertextual idad, "du plagiat". Forma que, para los efectos del análisis, trataremos como un especial tipo de relación transtextual, aquella que G enette llama hi pertextualidad: "J' entends par là touterelation unissant un texte B (quej' appellerai hypertexte) à un texte antérieur A (que j' appellerai, bien sûr hipotexte)... "48. Luego, para nosotros, el Texto A será La Pequeña Q uintrala de Joaquín Toesca y el Texto B, El sueño de la historia:

I. Partimos por mostrar, en forma clínica, "du plagiat":

1. M anuelita, la bella, le sirvió espárragos envenenados un mediodía aToesca. Al respecto Cádiz escribe en el Texto A: "En la comida le presentaría su plato favorito: espárragos. Recién comenzaba la estación..." 49 . Edwards, en cambio, escribe en el Texto B: "Los espárragos, los primeros de la esta- 
ción, ya estaban colocados en el puesto deToesca... "50.

2. M ientras Joaquín come su indigesto almuerzo, M anuelita, por supuesto, está nerviosa. Texto A: "Se dispuso a aguardar... apenas podía contener el temblor de sus manos y la garganta se le estrechaba como si el corazón se le hubiera subido hasta ahí... ${ }^{51}$. Texto B: "El señor se demoró muchos siglos, y ella, durante la espera, sentía que sus extrañas le ardían... "52.

3. Toesca nunca es comprendido ni por M anuela ni por la mamá de esa, al dios gracias, indisciplinada persona. El arquitecto se sienteincluso despreciado, Texto B: "Porque así lo trataban ella y su hija: deToesca, 0 a veces lo que era peor deTuesca... "53. Este dato lo obtuvo, el Texto B, de una declaración judicial hecha por la madre de $M$ anuelita, declaración que Cádiz recoge. Texto A: "C uando di en estado de matrimonio a mi referida hija, doña M anuela con don Joaquín Tuesca..." 54 .

4. Asistamos, ahora, a la vida de Toesca en Europa. Texto A: "El había estudiado bajo la dirección de otro experto, el maestro Francisco Sabatini... éste trabajaba para el príncipe de Nápoles y se llevó con él cuando se convirtió en Carlos III de España... a su vez Sabatini no quiso desprenderse de su alumno y colaborador Toesca y le pidió que lo acompañase... "55. Texto B: "Sus desvelos y sinsabores junto al arquitecto oficial de la corte de Carlos III, el caprichoso maestro Sabatini..."

5. El texto B anuncia que el "N arrador" "abrió uno de los libros del desván" 57 donde lee que a $M$ anuela se le encerraba por disi pada en distintos conventos: "M ás adelante la misma crónica agregaba para juntarse con sus 'amasios". Palabra que al "N arrador" estremece: "Amasios, probó la palabra, la paladeó, jA masios! repetía en un estado parecido al éxtasis..." "58. Confrontemos el Texto A: "Sufría junto a ella, su única manera de tenerla y no tenerla era encerrarla en un convento... para precaver al gún atentado que pueda executar con los amasios de la citada mi torpe esposa... "59. Parece que el libro del desván fuera el Texto A, a juzgar por las semejanzas.

${ }^{50} \mathrm{E}$ dwards, 2000, 104.

${ }^{51}$ Cádiz, 1993, 43.

${ }^{52} \mathrm{E}$ dwards, 2000, 105.

${ }^{53} \mathrm{E}$ dwards, 2000, 63.

${ }^{54}$ Cádiz, 1993, 12.

${ }^{55}$ Cádiz, 1993, 13.

${ }^{56}$ Edwards, 2000, 36.

${ }^{57}$ Edwards, 2000, 31.

${ }^{58}$ E dwards, 2000, 31.

${ }^{59} \mathrm{C}$ ádiz, 1993, 47. 
6. Texto A: “¿Cómo firmaba M anuela? La Fernández... "60.

Texto B: "M anuelita Fernández, La Fernández, como firmó algunas de sus cartas..." 61 .

7. Texto A: "Le asomaban giros italianos: 'que felice seria yo... '.

Texto B: "¿C ómo te Chiamas?...".

8. Unaúltima consideración: Cádiz para representar lo inasible de toda mujer escribe: "tenerla y no tenerla". Edwards, para referir esa indescifrable condición, anota: "cercana y lejana".

II. Ahora mostraremos, con un ejemplo, que existen secuencias enteras, la sustancia en realidad, del relato colonial en el Texto $B$ que están tomadas del Texto A:

1. Toesca se encuentra reunido con un comerciante que le ha encargado la construcción de su casa:

Texto A: (nombra al comerciante) "don Bernardo Yaneti".

Texto B: (Ilama al comerciante) "don Bernardo Llanete".

Ambos se encuentran en la sala de la casa del matrimonio Toesca- Pando cuando llega M anuela:

Texto A: "Sería cerca de las siete dela noche cuando regresó, casi una hora de pasada la cena..."

Texto B: “... como a las siete de la noche, entró D oña M anuela que venía de la calle muy dispuesta y con sus ropas mejores... "

Ahora, ¿de dónde sacó el Texto B que M anuela viniera tan elegante?

Texto A: (M anuela venía de un pasear con su amasio) “Para él se adornó con su mejor ropa: finas enaguas de cambray con delicados vuelos de encajes de España... piocha... lama de plata..."

Lo malo es que ella había hecho entrar por el patio del fondo al amasio, encerrándolo en una pieza, así es que cuando entró...

Texto A: "M anuela se sorprendió tanto que sólo atinó a saludarlos de paso, dirigiéndose a su dormitorio, donde la aguardaba G oycoolea. A quien N icolasa había hecho entrar con disimulo".

${ }^{60}$ Cádiz, 1993, 10.

${ }^{61}$ Edwards, 2000, 39. 
Texto B: "La M anuelita lo saludó con un monosílabo, pensando en otra cosa, sin darle siquiera la punta de los dedos, y salió a la carrera... "

Lo malo, de nuevo, es que M anuelita volvió a entrar a la sala, tras retozar con G oycoolea:

Texto A: "M anuela cometió la torpeza de asomarse al estrado, olvidando que se había quitado la ropa de paseo y puesto saya de casa, provocando azoramiento en don Bernardo y el evidente disgusto deToesca..."

Texto B: "La M anuelita volvió a entrar, desmelenada esta vez, sin la chaquetilla, con un corpiño de manga corta... - Señora - exclamó Toesca lívido... - N o se preocupe maestro - dijo don Bernardoyo me voy...".

Es obvio, no es cómodo para nadie asistir, con el marido, a un adulterio flagrante en contra de éste, menos aún cuando se está de visita:

Texto A: "No era para menos: acababa de cometer un acto impropio, faltando el respeto a un visitante de edad... ".

Texto B: “... ya desastrada y en traje de demasiada satisfacción, no correspondienteal cumplimiento que debía dar a don Bernardo... "62

El problema real se produce cuando se retira, al fin, el caballero:

Texto A: "Espantada, M anuela había huido al patio interior Ilevándose el farol...".

Texto B: "La M anuelita, a medio vestir, con el pelo suelto, con la palmatoria del velador en la mano, salió a la carrera y desapareció en el fondo del huerto...".

Ahora, el hechor, menos rápido, aún está en la pieza:

Texto A: "Toesca gritabaa las criadas quetrajesen luzy, por su lado, M anuela ordenaba a su esclava que sacase del cuarto el brasero encendido para evitar cualquier claridad...".

Texto B: "En el interior del dormitorio... sólo había un resplandor rojizo, el que'M inistraba un brasero de candela'... Toesca gritó Palmira...

${ }^{62}$ Astuto recurso de Edwards: Incluye como cita de una crónica de la época las referencias demasiado parecidas al Texto A. Buen intento, pero sólo es un truco. Y aun cuando no lo fuera, la fuente proviene de Cádiz, pues el texto de ella trae una completa guía de las referencias usadas en la construcción del relato. Actas de iglesias, archivos judiciales con nombre y número de causa, cartas de M anuelita, etc. 0 sea que, por lo menos, Cádiz es, insistimos, su fuente directa y podría agradecerle todo el trabajo ahorrado. Los años de estudio que queden para los periodistas españoles. 
era la más joven de todo el servicio... La M anuelita le hacía toda clase de gestos para que quitara el brasero de la pieza... ".

Es lógico que quisiera quitarlo, algo de luz debe haber proyectado sobre G oycoolea:

Texto A: "N icolasa y D olores, a las que llamaba Toesca no corrían a obedecerle... N icolasa trajo una candela y así él pudo distinguir un bulto en la cama. O rdenó, entonces, a D olores que sacase de la cama de su dueña una capa encarnada con una vuelta blanca... volvió turbada diciendo que no había tal capa... C omo Toesca insistiera, la criada se la trajo..."

Texto B: "Volví a gritonearla y la Palmira se me acercó temblando...

- ¡Saca esa cosa roja que hay en la cama!

Avanzó como una condenada y tocó el bulto rojo con la punta de los dedos, y arrancó, frenética... Eufemia grité... obedeció feliz y llegó y me entregó la capa que era roja como la sangre y tenía una vuelta blanca".

La cosa se pone buena, a G oycoolea ya no lo protege la capa encarnada con una vuelta blanca, roja con vuelta blanca para Edwards:

Texto A: "G oycoolea bajaba de la cama lleno de turbación y con voz trémula y expresiones mal articuladas pedía perdón. El marido... sujetó su mano, la del espadín, limitándose a tenderle la capa... "

Texto B: "G oycoolea, desnudo, con la vista baja, pálido como un muerto...

- ¡M aestro! ¡Por favor!

Con cara de miedo de súplica, de sumisión completa, y yo con el espadín en la mano... le ordené que se fuera"63.

Eso es todo.

La relación intertextual anterior se repite en otras secuencias del texto, por ejemplo:

- La captura y envío de M anuelita a un monasterio. Texto A páginas: 54 a 57; Texto B: 222-226.

- La golpiza dada por Toesca a M anuela y su amasio D íaz M uñoz en la plaza. Texto A: 68-69; Texto B: 316-317. Aquí encontramos un detalle muy interesante. Toesca se queda con el sombrero de D íaz M uñoz y se lo lleva a

${ }^{63}$ El relato anterior se ubica entre las páginas 49-51 del Texto A; y 207-211 del Texto B. 
casa, veamos qué nos dicen de aquél, Cádiz, primero, y Edwards, después:

Texto A: "El sombrero que Toesca conservó a los pies de su cama... "

Texto B: (El sombrero) "Lo deja caer en el suelo de tablas de su dormitorio, a los pies de su camastro..."

"Al que le venga el sayo que se lo ponga", pregona un refrán. En parodia anotamos: "Al que le venga el sombrero que se lo ponga".

Aparece, claramente, el plagio, el robo, como forma inferior de intertextual idad. Veamos ahora qué dice la teoría sobre tan común ejercicio, es decir, ese de andar robando.

\section{TERCERA AVEN IDA LOS SENTID OS DEL ROBO}

Julia K risteva, discípula avanzada, sostiene que "la escritura es contestación, robo, fractura, ironía... "64. Es el robo positivo. Pero creemosqueno seajusta esta concepción de robo positivo al caso que nos ocupa, por cuanto ella está hablando desde la formulación de su maestro: "H oy no existe ningún lugar del lenguaje exterior a la ideología burguesa... la única respuesta posible no es ni el enfrentamiento ni la destrucción, sino solamente el robo: fragmentar el texto antiguo de la cultura, de la ciencia, de la literatura y diseminar sus rasgos según fórmulas irreconocibles" 65 . Aquí se está hablando de una cosa muy distinta a despojar de su novela a una ancian ${ }^{66}$. Creemos que se nos está invitando a fragmentar el discurso dominante, el orden del discurso, diría Foucault. O rden configurado por el sistema de pensamiento "verdadero" en una época determinada. Y la fragmentación, el quiebre, no ocurre en El sueño de la historia, pues como ya vimos termina por entregarse al orden dominante disciplinando a sus personajes.

${ }^{64} \mathrm{~K}$ risteva, Julia. Sentido y sinsentido de la revuelta. Eudeba. Buenos Aires. 1998, p. 352.

${ }^{65} \mathrm{~K}$ risteva, 1998, 352. Citando a Barthes en: Barthes, Roland, Sade, Fourier, Loyola. Le Seuil. París. 1971.

${ }^{66}$ Este despojo hace no pertinentes al caso las tesis sobre el robo que expone $G$ ómez en Borges, Q uevedo, Paz. Allí sostiene que Borges y Paz "roban" a Q uevedo. No es lo mismo robar a Q uevedo que a Cádiz. Este mismo ensayo le ha robado y le seguirá robando a Barthes, D eleuze, Foucault, N ietzsche, D errida, Lyotard, Triviños, Rodríguez, 0 elker, 0 stria, Contreras, Zapata, Lermanda, Gallardo (autor del abstract que nos inaugura). No tiene nada de malo. A Borges no le robamos, una vez y para siempre lo asaltamos en un almacén de la pampa. 
O tra versión del robo la encontramos en D eleuze. Este filósofo sostiene: "Encontrar es hallar, capturar, robar... robar es lo contrario de plagiar, de copiar... ". N otamos que el robo sí es positivo, pero en el caso deabrir, generar un devenir. No una cesura ${ }^{67}$. El robo nos permite poblarnos, D eleuze lo dice mejor... "Somos desiertos pero desiertos poblados de tribus, de faunas y de floras... pero todas esas poblaciones no impiden el desierto que es nuestra ascesis misma, al contrario, lo habitan, pasan por él, sobre él... "68. Estas palabras lo dicen todo. Cada vez que robamos, poblamos nuestro desierto con el otro, inauguramos un devenir, una evolución aparalela. Sin embargo, continuamos en la más absoluta soledad, la tragedia del pensar: El robo sería entonces una especie de captura de un compañero, una compañera si somos afortunados, de viaje por el desierto, instancias fugaces, de gran posibilidad creadora... "bodas, pero no parejas, ni conyugalidad"69. "Tener un saco adonde meta todo lo que encuentro, a condición que también me metan a mí en el saco... ". Insistimos, el robo es un encuentro, cuyo requisito primero es robarnos a nosotros mismos. Robar es imbuncharse, meterse en un saco, devenir multiplicidad. O tro sentido del imbunche. Ya no el cuerpo lleno sin órganos, el cuerpo improductivo, sino el cuerpo, el imbunche, que usaban los Brujos de la M ayoría en C hiloé; el Cuerpo Sin O rganos que permite, que potencia, que hace circular las magias y los hechizos.

N os explicamos:

D eleuzey Guattari (siguiendo a Artaud) rondan el C so : “El cuerpo no es más que un conjunto de válvulas, cámaras, esclusas, recipientes, vasos comunicantes,... metrópolis que hay que manejar con un látigo; ese látigo es el al ma"70. Ese látigo que es el al ma asigna ciertas y determinadas funcionesa cada órgano. Ahora, si somos capaces de caminar con la cabeza, cantar con los senos, nasales, respirar con el vientre... estamos en condiciones de encontrar nuestro $\mathrm{CsO}{ }^{\prime \prime 7}$.

Artaud, en el mismo sentido, propone "ejercicios que nos instan a liberarnos en nosotros, dentro de nosotros de las trampas y demonios del poder. Intento que siempre ha provocado y provocará una conmoción en el afuera social", pues "el sistema teológico no puede soportar el CsO ... lo persigue y lo destripa para adelantarse y hacer que prevalezca el organis-

${ }^{67}$ Entendida en el sentido etimológico del término: coedere, cortar.

${ }^{68}$ D eleuze, Gilles. D iálogos. Pre-Textos. M adrid. 1980.

${ }^{69}$ Surge lo glacial en D eleuze, nada de emociones. $N$ o vengas con una compañera en el desierto. Recuerda que eres ascesis, nos parece decir.

70 D eleuze y Guattari. M il mesetas. Pre-Textos. M adrid. 1995, p. 157.

${ }^{71}$ D eleuze y Guattari, 1995, 159. 
mo"72. O rganismo instituido por el pequeño tirano y su "látigo", el alma, la cual se conecta en forma directa, alimenta, al gran dictador con el que intentamos poblar el afuera ${ }^{73}$ : el factor Dios.

Esa alma, esa construcción del poder, en la novela deEdwards tienenombre: "supranarrador", esél el organizador de losórganos del texto. Esél quien no deviene multiplicidad. Podría haber enviado a su narrador hard-boiled a buscar la novela de Cádiz, haberla metido al saco para poblar su desierto. Pero no, prefirió el imbunchamiento negativo, el suprimir al otro. El instalarse como el gran dictador deEI sueño de la historia. Y, así, iniciar su fracaso: Fracasa como genealogista, excluye finalmente al cuerpo, le teme. Fracasa como genealogista, pues esta praxis "exige un saber minucioso, gran cantidad demateriales recopilados, paciencia... cierto encarnizamiento en la erudición... se opone a la búsqueda del origen"74. No importa de donde venga Pinochet, no interesa Lacunza. Por ahí tampoco habría saltado la pus. No recopiló nada, sólo amplificó una historia de otra. Fracasa como genealogista porqueprefiereser historiador. "EI N arrador" descubreen el departamento del historiador un desván, oscuro... "una pieza rectangular rodeada de estanterías de madera tosca, donde había un asombroso hacinamiento de papeles... las fojas originales de un proceso de nulidad hacia fines del mil setecientos" (la causa de M anuelita). "EI N arrador" entra al mundo de los muertos, igual al "historiador demagogo" que Foucault describe en sus estudios del genio de la filosofía: "El demagogo está conducido a la negación del cuerpo con el fin de establecer la soberanía de una idea... tendrá que encarnizarse consigo mismo... imitar la muerte para entrar al reino de los muertos... "75. Es decir, el desván. El "supranarrador" no captó que el viaje hacia el otro, la otra, habría sido un viaje de vida, pensamos, por ejemplo, en el narrador hard-boiled bebiendo en el tren nocturno a Concepción (hubo juergas históricas en ese bar). El "supranarrador" prefiere enterrarlo en un desván (un reclutorio). Y de paso intentar el crimen perfecto, la supresión del otro. Pero, afortunada-

${ }^{72}$ D eleuze y G uattari, 1995, 159.

${ }^{73}$ Entendemos este término en el sentido propuesto por Foucault, es decir, esa zona de turbulencias que es necesario plegar. D e no hacerlo el hombre se ahoga, se muere. Por ello es que pensó, se intentó, Ilenar ese espacio con un dios. El concepto anterior de afuera, es decir social, que usamos se corresponde más bien con la idea de D el euze, un afuera que es simplemente lo exterior al hombre. Por ejemplo hablando de nómadas, dice que su relación con el afuera es directa, viven en el afuera y no le "temen".

Lo importante, en todo caso, es que después de $\mathrm{N}$ ietzsche el afuera se quedó sin dictador. Ahí está el peligro de armarse un C SO , descubrir que al pequeño dictador se le murió el jefe. Y encontrarse con que más allá hay una pura ausencia.

${ }^{74}$ Foucault, 1992, 8.

${ }^{75}$ Foucault, 1992, 24. 
mente, el crimen jamás es perfecto, nos enseña Baudrillard. Y al gún día llegará la revancha del pueblo de los espejos, la gran revancha de la alteridad... "todo lo que sirve de reflejo pasivo a un mundo idéntico está dispuesto a pasar a la contraofensiva..."

La próxima vez queEI sueño dela historia se mire en el espejo verá reflejada la portada de La Pequeña Q uintrala de Joaquín Toesca.

\section{AVENIDA DEL FIN}

Así una vez más el azar operó sobre la vida de los humanos, uniendo, para siempre, a dos textos leídos de modo sucesivo y casual... ¿y si no hubiésemos conversado con 0 scar Lermanda sobre la novela de Edwards?... ¿Y si el escritor consagrado hubiera puesto una simple nota en su novela "maestra"? Algo así como... "Este texto dialoga con una novela olvidada". Con ello bastaba, de hecho habría inaugurado un desafío para la arqueología crítica: encontrar a Cádiz y su cándida forma denarrar. 0 quizás, siendo más fino pudo inventar un personaje que se llamara IIda, pero no lo hizo, desgraciadamente no.

Por la calleM aipú, en Concepción, entre los humos de microbuses, talleres de autos y orines de borrachos terminales que pueblan bares oscuros se puede observar, tras unas rejas oxidadas, un patio y al fondo, un zaguán. Allí vivía una mujer que escribía cuentos para niños en el diario EI Sur. Cierta vez intentó una historia para grandes, quiso ser grande... "yo le puse apodo, yo la encontré", dijo de su "Pequeña Q uintrala", la M anuelita. Edwards robó el hallazgo sin temor, incluso llama a la mujer de Toesca con el mismo apodo: "Pequeña Q uintrala". Cádiz murió sola y olvidada. El mundo literario no acusó recibo de su libro. Edwards publicó El sueño de la historia y el mundo literario se asombró y los diarios publicaron reseñas, incluso antes de su aparición.

Asistimos entonces a un espectáculo común en nuestra cultura: el otricidio. Y con éste la imposición de lo uno y de lo mismo.

Sin embargo, sabemos queel otro siempre reaparece, quea pesar de todos los esfuerzos por eliminarla, la alteridad persiste... los huesos de los desaparecidos asoman en las pampas.

La novela de Cádiz soportó la oscuridad, luego la negación. I ncluso resistió el incendio de su casa editora y, con el siniestro, la incineración de muchos de los pocos ejemplares que sumaron su única tirada (300).

H oy, el, quizás, último de aquéllos surge inocente.

${ }^{76}$ Baudrillard, Jean. El crimen perfecto. Anagrama. Barcelona. 1996, 191 pp. 


\section{BIBLIOGRAFIA}

Barthes, Roland. 1973. "Analysetextuelle d' un conted' Edgar Poe". En: Alexandrescu,

Barthes, Bremond et alli. Semiotique narrativè et textuelle. Larousse, Paris, p. 29.

Baudrillard, Jean. 1996. El crimen perfecto. Anagrama. Barcelona.

Borges, Jorge Luis. 2000. O bras completas. Emecé. Buenos Aires.

Cádiz Avila, Ilda. 1994. La Pequeña Q uintrala deJ oaquín Toesca. Editora Aníbal Pinto

S.A. Concepción.

D eleuze, Gilles. 1980. Diálogos. Pre-Textos. Valencia.

Guattari).

Edwards, Jorge. 1998. El sueño de la historia. Tusquets. Barcelona.

Concepción.

Foucault, M ichel. 1992. D e lenguaje y literatura. Paidós. Barcelona.

G enette, G érard. 1982. La Litterature au Second D egré. Editions du Seuil. París.

---------. 1978. Figures III. Editions du Seuil. París.

H utcheon, Linda. 1981. "Ironie, satire, parodie". Poétique 46.

K risteva, Julia. 1969. "N arración y transformación”. En Semiótica N o 4. París.

--------- . 1969. Recherches pour une Sémanalyse. Editions du Seuil. París.

M icrosoft. 2000. Diccionario Encarta.

- - 2000. Encidopedia Encarta.

M ujica, Bárbara. 2001. Reseña: El sueño dela historia, en Americas. Washington. M arsApril.

N ietzsche, Federico. 1984. Genealogía dela moral. Fondo de Cultura Económica. M éxico.

Pérez Bowie, José. "¿La inviabilidad de la novela histórica? La saga de los M arx de Juan

G oytisolo". En: La novela histórica defines del siglo XX. José Romera Castillo et alli, pp. 339-349.

Piglia, Ricardo. 1992. Respiración artificial. Planeta.

Rodríguez, M ario. 2000. Curso: “Borges, Paz, Piglia”. D octorado en Literatura. Inédito. Universidad de Concepción.

Rojas, Carlos. 1978. El valle de los caídos. D estino. Barcelona.

Romera Castillo et alli. La novela histórica de fines del siglo XX.

Serrano, Samuel. 2000. Reseña: "El sueño dela historia". En: Cuadernos H ispanoamericanos. Septiembre.

Suleiman, Susan. 1979. "La structure d' apprentissage". Poétique N 37. Febrero.

Todorov, Tzvetan. 1970. Barthes, B remond, Greimasy otros. Análisis estructural. Fondo de Cultura Económica. M éxico.

---------. 1982. M ikhail Bakhtine: Le principe dialogique Editions du Seuil. París.

Vázquez M ontal bán, M anuel. 1992. Autobiografía del general Franco. Planeta. Barcelona. 